\title{
Abstract
}

Background-Symptoms of autism spectrum disorder (ASD) and inattention (IA) are highly comorbid and associated with deficits in executive cognition. Cognitive deficits have been posited as candidate endophenotypes of psychiatric traits, but few studies have conceptualized cognitive deficits as psychiatric comorbidities. The latter model is consistent with a latent factor reflecting broader liability to neuropsychological dysfunction, and explains heterogeneity in the cognitive profile of individuals with ASD and IA

Methods-We tested competing models of covariance among symptoms of ASD, IA, and cognition in a sample of 73 youth with a known genetic mutation

Results-A common executive factor fit best as a cognitive comorbidity, rather than endophenotype, of the shared variance between measures of IA and ASD symptoms. Known genetic risk explained a third of the shared variance among psychiatric and cognitive measures

Conclusions-Comorbid symptoms of ASD, IA and cognitive deficits are likely influenced by common neuro-genetic factors. Known genetic risk in ASD may inform future investigation of putative genetic causes of IA.

\section{Comorbid Inattention in Autism Spectrum Disorder}

Autism spectrum disorder (ASD) and attention deficit hyperactivity disorder (ADHD) are two of the most common neurodevelopmental disorders, affecting approximately $2 \%$ and $7 \%$ of school age children, respectively (Blumberg et al., 2013; Willcutt, 2012). ASD is characterized by deficits in social communication and restricted and repetitive behaviors and interests, while hallmarks of ADHD are symptoms of inattention, impulsivity and hyperactivity (APA, 2013). Despite these seemingly disparate symptom clusters, there is a

Correspondence to: Anne B. Arnett, Ph.D., University of Washington, CHDD Box 357920, Seattle, WA 98195,

Arnett.anne@gmail.com, p. (978) 886-1658.

CONFLICT OF INTERESTS

E.E.E. is on the scientific advisory board (SAB) of DNAnexus, Inc. 
high degree of comorbidity, such that $20-50 \%$ of individuals with ASD show comorbid symptoms of ADHD (Simonoff et al. 2008; Di Martino et al., 2013; Sinzig, Walter \& Doepfner, 2009). Likewise, children with ADHD have persistent social difficulties (Arnett, MacDonald \& Pennington, 2013) and tend to score higher than average on behavioral questionnaires targeting core ASD symptoms (Reiersen, Constantino, Volk \& Todd, 2007).

Several theories have been proposed to explain comorbidity between ASD and ADHD, including the notion that executive dysfunction is a cognitive endophenotype reflecting neural atypicalities underlying both disorders (Charman et al., 2011; Ozonoff, Pennington \& Rogers, 1991; Rommelse et al., 2009). An endophenotype is a measurable construct that mediates the path from genetic risk to behavior (Gau \& Shang, 2010), and as such serves as a proxy for neurodevelopmental differences that are more directly tied to genetic expression. Both ASD and the Inattention (IA) symptom domain of ADHD have been well characterized with regard to cognitive deficits; executive functions (e.g. inhibition, planning, flexibility) are repeatedly named as candidate cognitive endophenotypes of each disorder (Nydén, Hagberg, Goussé, \& Rastam, 2011; Gau \& Shang, 2010). Processing speed and inhibitory control are particularly strong predictors of IA when multiple cognitive factors are included in a model (McGrath et al., 2011). The literature is mixed as to whether a double dissociation exists regarding ASD and IA cognitive profiles. Several studies (Ozonoff \& Jensen, 1999; Pennington \& Ozonoff, 1996; Sinzig, Morsch, Bruning, Schmidt \& Lehmkuhl, 2008) have reported that ASD is associated with planning and cognitive flexibility deficits, but intact inhibition and working memory. Adamo and colleagues (2014) found that variability in reaction time was specific to IA, with or without comorbid ASD. Van der Meer and colleagues (2012) reported that working memory and cognitive style of primary IA with comorbid ASD differed from primary ASD with comorbid IA. Still others have reported fewer distinctions between the two disorders (Corbett, Constantine, Hendren, Rocke \& Ozonoff, 2009; Goldberg et al., 2005; Geurts, Verte, Oosterlaan, Roeyers \& Sergeant, 2004; Hill \& Bird, 2006; Nydén, Gillberg, Hjelmquist, \& Heiman, 1999).

Notable limitations to most of these studies have been 1) inclusion of only high functioning individuals with ASD, which may obscure important observations about comorbidity in this population; and 2) use of dichotomous diagnostic categories to characterize ASD and IA comorbidity, which decreases power to estimate covariance across continuous symptom dimensions. The current study addresses these gaps by measuring the covariance of continuous scales of ASD and IA symptoms. We focused on the IA symptom domain in ADHD due to its pervasiveness across development and stronger association with cognitive deficits (Lahey, Pelham, Loney, Lee \& Willcutt, 2005).

The concept of a general psychopathology factor, " $P$," has been proposed to explain covariance across psychiatric traits (e.g. Caspi et al., 2014; Tackett et al., 2013). Like the general cognitive factor, $g$ (Spearman, 1927), $P$ is a latent factor that estimates shared variance across behavioral traits and is thought to reflect complex, underlying neurodevelopmental characteristics. Previous research indicates that $g$ and $P$ are correlated (Caspi et al., 2014), and variance in $P$ can be partially accounted for by cognitive skills. For example, McGrath and colleagues (2016) demonstrated that shared variance among psychosis, mania, and autistic traits was partially explained by a common executive 
cognition factor. This model is consistent with a cognitive endophenotype model and indicates that measures of cognition are more closely tied to brain functions that give rise to the abnormal psychiatric phenotype.

In the present study, we propose an alternative model to explain the association between cognitive and psychiatric traits. In this model, $P$ is an underlying, neurodevelopmental liability that influences the shared variance across all three cognitive and psychiatric traits, i.e. ASD symptoms, IA and cognition. Like the cognitive endophenotype model, this cognitive correlate model assumes that all three traits share common neuro-genetic etiology. Unlike the cognitive endophenotype model, the correlate model does not place cognition as a mediator of the association between genetic and psychiatric expression. In practice, this means that an individual could show severe psychiatric traits with relatively intact cognitive skills. The correlate model is consistent with findings that executive cognition only accounts for 35\% of the behavioral variance in ADHD symptoms (McGrath et al., 2011), executive deficits are neither necessary nor sufficient to cause ADHD (Willcutt, Doyle, Nigg, Faraone \& Pennington, 2005), and only a portion of individuals with ASD have intellectual disability (Matson \& Shoemaker, 2009).

A major limitation to testing cognitive endophenotype models of psychiatric comorbidity is a lack of clearly identified genetic risk. Known single-gene and copy number variation (CNV) mutations now account for approximately 10-30\% of autism diagnoses (Iossifov et al., 2012; Krumm et al., 2015), while in contrast, genome-wide association and candidate gene studies of ADHD have failed to identify any single genes with large effects (Neale et al., 2010; Todd et al., 2005). High heritability estimates $\left(h^{2}=.76\right.$; Faraone \& Doyle, 2001) and high prevalence rates of IA are consistent with a polygenic etiology, i.e. suggesting lack of putative single gene events. On the other hand, failure to identify single gene events may relate to a lack of routine clinical genetic testing with ADHD, as well as heterogeneity of the disorder, which dilutes power to identify putative genetic causes (Fair, Bathula, Nikolas \& Nigg, 2012; Karalunas et al., 2014). Although there is scant evidence for specific linkage loci or shared candidate genes across IA and ASD (Rommelse et al., 2009), pleiotropic effects for single nucleotide polymorphisms (SNPs) and large, rare CNVs at common genetic loci do support a high degree of overlapping genetic risk (Taurines et al., 2012). Comparisons of functional gene network analyses for each disorder implicate gene pathways involved in synaptogenesis and neuronal growth and differentiation (Gilman et al., 2011; Poelmans, Pauls, Buitelaar \& Franke, 2011). The growing list of known genetic events associated with ASD thus presents an opportunity to search for a subset of those genes that also confer risk for IA.

\section{Current Study}

The current study aimed to clarify the origin of covariance among symptoms of ASD, IA and executive dysfunction. Our sample was unique in that all individuals had a likely gene disrupting mutation (LGDM) on a gene that had previously been associated with ASD. In the current study, we hypothesized that a subset of disrupted genes in this sample were also associated with elevated IA symptoms and that this subset of genetic events would explain shared variance between symptoms of ASD and IA. Thus, the first goal was to test whether 
known genetic risk (defined as an event on the subset of genes associated with elevated IA) could explain shared variance between symptoms of ASD and IA. Secondly, we tested alternative models that placed executive cognition as either 1) an endophenotype mediating the effect of genetic risk on shared variance between ASD and IA symptoms, or 2) a correlate of ASD and IA symptoms, with covariance across all three traits explained by genetic risk.

\section{Methods}

Procedures

Individuals aged 3-22 years old were recruited for participation following identification of an LGDM that has previously been associated with ASD (O'Roak et al., 2011; O'Roak et al., 2014). Enrollment exclusion criteria included known syndromic disorder associated with ASD (e.g. Fragile X). Fourteen individuals were unable to complete cognitive testing due to living outside the United States ( $n=5)$, failure to return behavioral questionnaires $(n=1)$, or behaviors that interfered with cognitive testing $(n=8)$. The final sample comprised 73 individuals (see Table 1 for participant demographics). Testing took place in the laboratory or in the participant's home over the course of two days. Parents completed questionnaires about their child's behavior and participated in interviews including the Autism Diagnostic Interview Revised (ADI-R; Rutter, Le Couteur, \& Lord, 2003), the Vineland Adaptive Behavior Scales, $2^{\text {nd }}$ Edition (Sparrow, Cicchetti \& Balla, 2005) and a family and medical history. Parents and participants age 13 and older provided written consent, and younger youth provided verbal or written assent, as developmentally appropriate. All procedures were in compliance with the University of Washington Institutional Review Board.

Autism Diagnosis-A DSM-5 (APA, 2013) diagnosis of ASD was assigned based on clinical consensus of a licensed psychologist following administration of the Autism Diagnostic Observation Schedule, $2^{\text {nd }}$ Edition (ADOS-2; Lord, Rutter, \& DiLavore, 2012) and the ADI-R by clinicians demonstrating research reliability on these measures. Caregivers also completed the Social Responsiveness Scale, $2^{\text {nd }}$ edition (SRS-2; Constantino $\&$ Gruber, 2005). The SRS-2 total T-score $(M=50, S D=10)$ was used as a continuous measure of ASD symptoms, following previous findings that this measure is correlated with the ADI-R (Murray, Mayes \& Smith, 2011) and ADOS-2 (Pugliese et al., 2015). However, given debate regarding the specificity of elevated SRS-2 scores to ASD as opposed to other behavioral disorders (Hus, Bishop, Gotham, Huerta \& Lord, 2013a, 2013b), we henceforth refer to this measurement as SRS-2, rather than ASD.

Inattentive Symptoms-As ADHD was not the primary focus of the recruitment study, a thorough diagnostic evaluation was not conducted. However, parents completed the Child and Adolescent Symptom Inventory - 5 (CASI-5; Gadow \& Sprafkin, 2015), which includes explicit evaluation of the 18 DSM-5 ADHD symptoms. Additionally, caregivers completed the age appropriate version of the Achenbach Behavior Checklist (i.e. Child Behavior Checklist 1.5-5, Child Behavior Checklist 6-18, or Adult Behavior Checklist; Achenbach \& Rescorla, 2000; 2001). The Achenbach checklists include an attention problems subscale that is predictive of DSM diagnoses of ADHD Primarily Inattentive and Comorbid subtypes 
(Eiraldi, Power, Karustis \& Goldstein, 2000; Ostrander, Weinfurt, Yarnold \& August, 1998). For the present study, Elevated IA was defined as six or more CASI-5 ADHD inattention symptoms and a clinically elevated Achenbach attention problems scale (T-score 270 ). The continuous measure of IA severity was defined as the mean of the CASI-5 inattentive severity and Achenbach attention problems T-scores.

Cognitive Factors-The cognitive battery was designed to ascertain a broad range of cognition and included the Differential Ability Scales, $2^{\text {nd }}$ Edition (Elliott, 2007), California Verbal Learning Test $-2^{\text {nd }}$ Edition and Child Versions (Delis, Kramer, Kaplan, \& Ober, 1994; 2000), Expressive Vocabulary Test $2^{\text {nd }}$ Edition (Williams, 1997), Peabody Picture Vocabulary Test, $4^{\text {th }}$ Edition (Dunn \& Dunn, 2007), and selected subtests from the DelisKaplan Executive Function System (Delis, Kaplan, \& Kramer, 2001) and NIH Toolbox (Weintraub et al., 2013). Full scale IQ was derived from the DAS-II general cognitive abilities composite. Exploratory and confirmatory factor analyses were used as complementary approaches to obtain theoretically- and data-driven cognitive factors (see supplementary Table S1, Notation S1, Table S2, and Figure S1). We found four latent factors: verbal memory, verbal fluency, visual-spatial processing, and common executive (CE). Similar to previous research (McGrath et al., 2016), CE was created as a broad factor reflecting inhibition, switching, and processing speed because we did not find support for distinction among these constructs in our analysis.

Genetic data-ASD-associated LGDMs were identified with family-based exome sequencing studies (Iossifov et al., 2014), or companion molecular inversion probe-based (MIP) targeted resequencing of potential ASD loci (O'Roak et al., 2014; O'Roak et al., 2011). Primary gene events in our sample spanned 31 genes and multiple effects, including frameshift, stop-gained, splice site acceptor, splice site donor, and missense (see Supplementary Table S3).

Structural Equation Modeling-Confirmatory factor analysis and structural equation models were conducted in Mplus 7.31 (Múthen \& Múthen, 1998-2012), which uses full information maximum likelihood (FIML) as a default approach to estimating models with missing data. Covariance coverage ranged from .37 to .95 for the cognitive and behavioral variables. The primary reason for missing data was inability of the participant to complete some component of psychometric testing. Model fit was evaluated using the following indices: Chi square $p>.05$, Comparitive Fit Index (CFI) $>0.95$ and Standard Root Mean Residual (SRMR) <.08 (Loehlin, 2004). Nested models were compared using the Bayesian Information Criterion (BIC), with lower values indicating better fit (Jung \& Wickrama, 2008).

\section{Results}

\section{Rates of ASD and Elevated IA}

Eighty-nine percent ( $\mathrm{n}=65)$ of our sample received an ASD diagnosis and of these, 31\% $(n=20)$ also demonstrated Elevated IA symptoms. Seven participants showed Elevated IA but no ASD, and one participant had neither Elevated IA nor ASD. All eight participants 
without ASD had a diagnosis of intellectual disability or global developmental delay. Among the ASD-only group, IA severity was still higher than the normative population: $M=$ $63.5, S D=8.51(t[44]=10.65, \mathrm{p}<.001)$.

\section{IA Risk Genes}

To examine associations between specific LGDMs and Elevated IA, we conducted exploratory analyses to look for patterns of Elevated IA within specific gene disruptions. Eleven of the 31 genes involved in LGDMs in our sample were associated with at least one participant with Elevated IA (Figure 1). We categorized those eleven genes as "IA Risk Genes." IA Risk Gene versus LGDM without IA Risk sample demographics are listed in Table 1. More than half the sample had an event on an IA Risk Gene ( $\mathrm{n}=47)$. Of those, only $57 \%(\mathrm{n}=27)$ actually showed Elevated IA $(M=79.28, S D=6.39)$. However, the remaining 20 individuals with an IA Risk Gene event who did not cross the threshold for Elevated IA still had IA severity in the borderline range ( $M=68.85, S D=8.07$ ), which was significantly higher than participants with an LGDM without IA Risk $(M=61.35, S D=8.30 ; t(44)=2.26$, $p=.029)$. Thus, our IA Risk Gene categorization was associated with greater risk of high IA.

\section{IA and SRS-2 Shared Variance}

The correlation between SRS-2 and IA severity was moderate in magnitude $(r=.66, p<$. 001). We modeled a latent psychopathology factor, $P$, reflecting the shared variance between SRS-2 and IA, and tested a structural equation model with the dichotomous predictor IA Risk Gene (vs. LGDM without IA Risk) directly predicting $P$. The model explained $32 \%$ of variance in $P$ (Figure 2A), indicating that an event on an IA Risk Gene explained about onethird of the covariance between SRS-2 and IA severity.

\section{CE as Cognitive Endophenotype}

Prior to testing our endophenotype model, we aimed to determine that $\mathrm{CE}$ was in fact a candidate endophenotype of IA in our sample. We hypothesized that if $\mathrm{CE}$ is a cognitive endophenotype of IA, disruptions to IA Risk Genes would confer unique deficits on the CE factor, even among the group of individuals with an IA Risk Gene event who had subthreshold IA symptoms. Contrary to expectations, the IA Risk Gene group performed lower on all four cognitive factors ( $p \leq 001$; Table 2 ). This remained true even when we dropped individuals who had Elevated IA from the analysis (p's<.05), indicating that disruption to an IA Risk Gene was associated with greater risk of broad cognitive impairment, regardless of IA symptom severity.

Next, we compared individual path models in which the effect of IA Risk Gene on $P$ was mediated by each of the four cognitive factors (Figure S2) to test for specificity of the CE factor. The models each showed excellent fit (Chi Square $p>.05$, CFI $>.98, \mathrm{SRMR}<.03$ ). The CE factor explained the greatest amount of variance in $P(42 \%)$, although the visual-spatial and verbal fluency factors were also good predictors, explaining $38 \%$ and $40 \%$ variance, respectively. However, given substantial literature pointing to unique deficits in CE-related tasks in youth with symptoms of IA and ASD, we elected to focus on CE in subsequent models. 


\section{Cognitive Endophenotype versus Cognitive Correlate Models}

The question of whether CE constitutes an endophenotype, versus correlate, of the covariance between SRS-2 and IA can be uniquely addressed in our sample where we have high confidence in the genetic etiology of the ASD symptoms. To this end, we next compared the results of the cognitive endophenotype model (Figure $2 \mathrm{~B}$ ) to a cognitive correlate model (Figure 2C) wherein $P$ reflected the shared variance among IA, SRS-2 and CE. Both models had excellent fit; however, the BIC was slightly lower for the cognitive correlate model, indicating better fit. IA Risk Gene explained 36\% of the variance in $P$ in the cognitive correlate model, suggesting more than one-third covariance across all three traits can be explained by known genetic risk in this sample. Moreover, when we added a direct effect from genetic risk to the residual variance in CE (Figure 2D), the path was not statistically significant, indicating that all of the effect of IA Risk Gene on CE is accounted for by $P$. In other words, the genetic risk in this model is only associated with CE to the extent that CE covaries with IA and SRS-2. Altogether, these models suggest deficits in CE are not an endophenotype, but rather reflect comorbidity with IA and SRS-2 in our sample of individuals with LGDMs.

\section{Discussion}

We examined evidence for shared genetic risk associated with SRS-2 and IA comorbidity using a sample of youth with a known LGDM previously associated with ASD. Consistent with prior research that has used a behavior-based approach to associate particular gene disruptions with ASD (O'Roak et al., 2011), we categorized a subset of eleven genes based on their association with Elevated IA in our sample. These IA Risk Genes accounted for $32 \%$ of the shared phenotypic variance between SRS-2 and IA, and 36\% of the shared variance among SRS-2, IA and CE. Across all models, a greater proportion of IA was explained than SRS-2 severity, suggesting that there are additional, unmeasured genetic and environmental risk factors that influence SRS-2 symptoms. Individuals with an event on one of the IA Risk genes showed greater cognitive impairment and higher IA severity, whether or not their IA symptoms crossed the research diagnostic threshold. This might imply that the IA Risk Genes constitute genes of greater global impact on neurodevelopment; however LGDMs without IA Risk in this sample were also strongly associated with intellectual disability in this and previous datasets (e.g. ARID1B; McRae et al., 2017). Altogether, IA Risk Genes appear to reflect unique neurodevelopmental liability related to IA.

Given the heterogeneity of genetic events associated with ASD, a logical model of SRS-2 and IA covariance is one in which multiple gene variants converge on a cognitive endophenotype, such as $\mathrm{CE}$, which serves as a proxy for atypical neurodevelopment resulting from shared genetic risk. However, prior studies are inconclusive regarding common cognitive deficits across ASD and ADHD diagnoses, and our results suggest that CE deficits may be better conceptualized as a comorbid trait. In our cognitive correlate model, covariance across SRS-2, IA and CE was explained by disruption to IA Risk genes, while residual variance for each trait was presumably explained by additional, unmeasured genetic and environmental factors. This is not to imply that a deficit in CE represents a separate clinical disorder; the near ubiquity of CE deficits in neurodevelopmental disorders 
argues against its validity as a standalone diagnosis. Instead, the cognitive correlate model supports the notion of trait covariance over categorical comorbidity. Notably, the cognitive endophenotype model also demonstrated good fit to the data and LGDM are rare, particularly in ADHD. Thus, future research should also aim to test these competing models using behavioral genetic approaches, such as twin analyses.

Our study applied the concept of $P$, a general psychopathology factor that has gained increasing support in the literature as an explanation for high rates of comorbidity among childhood-onset disorders (Borsboom, Cramer, Schmittmann, Epskamp \& Waldorp, 2011). Historically, $P$ represents vulnerability to all psychiatric traits, but in the current study, $P$ only captured shared variance across IA, SRS-2, and CE. Thus, it is unclear to what extent $P$ in our study reflects a unique comorbidity, as opposed to one aspect of an overarching general psychopathology factor. Future studies should aim to include additional comorbidities, such as anxiety and depression, as well as additional cognitive deficits, to test the specificity of the IA and SRS-2 overlap.

The current study contributes to a growing body of research indicating that comorbidity is the rule, rather than the exception, in neurodevelopmental disorders (Van Steensel, Bögels \& de Bruin, 2013). At the same time, clinical services are becoming highly specialized, and families endure extremely long wait times for a diagnosis of ASD only to be sent elsewhere for further evaluation of ADHD, anxiety, depression and learning disorders (Austin et al., 2016; Gordon-Lipkin, Foster \& Peacock, 2016). The notion of a common psychopathology factor, whether explained by a single gene event or polygenic factors, introduces a conflict between specialized versus comprehensive treatment centers for children with neurodevelopmental disorders. The current results imply that even within specialized services, clinical practice should be comprehensive, and emphasize trait continua over diagnostic classification, in line with research initiatives such as the NIMH research domain criteria (RDoC; Insel, 2014).

Use of the SRS-2 as a measure of ASD symptom severity may be considered a limitation in the current study due to prior documentation of elevated SRS-2 scores among youth with ADHD and other behavioral challenges (Reiersen et al., 2007; Hus et al., 2013a). The SRS-2 contains 8 items (out of 65) that appear to overlap with ADHD symptom criteria, such as "seems more fidgety in social situations" and "stares or gazes off into space." However, Reierson et al. (2007) found that individuals with ADHD still demonstrated elevated symptoms on the SRS-2 when these items were removed, indicating that ADHD symptoms were not driving this result. A lack of normative data for those subscales precluded their use in the current study; however, future research could benefit from use of scales that are more independent from one another.

The present study was unique in that we included participants with a broad range of IQ. However, our low-IQ group showed high correlations among the cognitive factors. Relatedly, we were unable to identify distinct executive function factors in our CFA (consistent with some prior research even among youth with average intellectual functioning, i.e. McGrath et al 2016; Miyake et al., 2000) and verbal fluency and visualspatial factors also showed excellent fit as cognitive endophenotypes; thus, our results may 
not be specific to CE. Previous research supports a common intelligence factor, g, that explains a great deal of variance in cognitive performance and is highly correlated with $P$ (Caspi et al., 2014); thus, these limitations likely reflect true covariance across cognitive measures in individuals with neurodevelopmental symptoms.

Relatedly, our sample did not contain a sufficient number of participants to test the structural equation models separately within an average-range FSIQ group. Among individuals with average-range FSIQ, the putative genetic event may be less impactful, allowing for greater effects of other genetic and environmental factors on development. High-IQ individuals warrant further study to investigate protective factors or specific genetic variants that relate to better outcomes.

In the current study, we characterized gene groups according to behavioral expression. Notably, many of our affected gene groups only included a single participant ( $n=17 / 31)$, so there is likely a degree of error to classification of our IA Risk Genes. Moreover, although all gene variants were likely disruptive, they were not identical across individuals even within a common gene group. The presence of additional "secondary" genetic hits, such as single nucleotide and copy number variants, was not considered, and such events are highly implicated in both ASD and ADHD (Taurines et al., 2012). The resulting IA Risk Gene group did not clearly correspond to known ontological subtypes, such as genes involved in chromatin modification (Iossifov et al., 2014; enhanced understanding of gene ontology will facilitate more targeted modeling of genetic risk in the future.

Interestingly, we identified seven individuals with Elevated IA but not ASD in our sample. Currently, an ADHD diagnosis alone does not prompt genetic testing in clinical settings, and candidate gene studies of ADHD have not yielded putative causal genetic variants of large effect (Neale et al., 2010; Todd et al., 2005). Our results suggest genes involved in putative genetic events previously associated with ASD may be worthwhile targets in future studies of ADHD. Along that line, all individuals with LGDM without IA Risk gene events received a diagnosis of autism, while only $83 \%$ of the IA Risk Gene group received that diagnosis. Thus, genes in our LGDM without IA risk group may confer specific risk for core ASD symptoms and warrant further attention.

\section{Conclusions}

A subset of known genetic mutations associated with both ASD and Elevated IA explained a substantial portion of the covariance across SRS-2 and IA symptom severities. Associated cognitive deficits associated with are most likely correlates, influenced by common neurodevelopmental vulnerability, rather than endophenotypes mediating the effect of genetic expression on behavior. Known genetic risk in ASD may inform future investigation of putative genetic causes of ADHD.

\section{Supplementary Material}

Refer to Web version on PubMed Central for supplementary material. 


\section{Acknowledgments}

We thank the individuals and their families for participation in this study. This research was supported in part by grants from the National Institutes of Health: R01MH101221 to E.E.E. and R01MH100047 to R.A.B. E.E.E. is an investigator of the Howard Hughes Medical Institute.

\section{References}

Achenbach, TM., Rescorla, LA. ASEBA preschool forms \& profiles. Burlington, VT: University of Vermont, Research Center for Children, Youth, \& Families; 2000.

Achenbach, TM., Rescorla, LA. ASEBA school-age forms \& profiles. Burlington, VT: University of Vermont, Research Center for Children, Youth, \& Families; 2001.

Adamo N, Huo L, Adelsberg S, Petkova E, Castellanos FX, Di Martino A. Response time intra-subject variability: commonalities between children with autism spectrum disorders and children with ADHD. European Child \& Adolescent Psychiatry. 2014; 23(2):69-79. [PubMed: 23716135]

American Psychiatric Association. Diagnostic and statistical manual of mental disorders (DSM- $5^{\circledR}$ ). American Psychiatric Pub; 2013.

Arnett AB, MacDonald B, Pennington BF. Cognitive and behavioral indicators of ADHD symptoms prior to school age. Journal of Child Psychology and Psychiatry. 2013; 54(12):1284-1294. [PubMed: 23848372]

Austin J, Manning-Courtney P, Johnson ML, Weber R, Johnson H, Murray D, ... Murray M. Improving access to care at autism treatment centers: a system analysis approach. Pediatrics. 2016; 137(Supplement 2):S149-S157. [PubMed: 26908470]

Borsboom D, Cramer AO, Schmittmann VD, Epskamp S, Waldorp LJ. The small world of psychopathology. PloS one. 2011; 6(11):e27407. [PubMed: 22114671]

Blumberg SJ, Bramlett MD, Kogan MD, Schieve LA, Jones JR, Lu MC. Changes in prevalence of parent-reported autism spectrum disorder in school-aged US children: 2007 to 2011-2012. National health statistics reports. 2013; 65(20):1-7.

Caspi A, Houts RM, Belsky DW, Goldman-Mellor SJ, Harrington H, Israel S, ... Moffitt TE. The p factor: One general psychopathology factor in the structure of psychiatric disorders? Clinical Psychological Science. 2014; 2(2):119-137. [PubMed: 25360393]

Charman T, Jones CR, Pickles A, Simonoff E, Baird G, Happé F. Defining the cognitive phenotype of autism. Brain research. 2011; 1380:10-21. [PubMed: 21029728]

Constantino, JN., Gruber, CP. Social responsiveness scale (SRS): Manual. Los Angeles, CA: Western Psychological Services; 2005.

Corbett BA, Constantine LJ, Hendren R, Rocke D, Ozonoff S. Examining executive functioning in children with autism spectrum disorder, attention deficit hyperactivity disorder and typical development. Psychiatry Research. 2009; 166(2):210-222. [PubMed: 19285351]

Delis, DC., Kaplan, E., Kramer, JH. Delis-Kaplan executive function system (D-KEFS). Psychological Corporation; 2001.

Delis, DC., Kramer, JH., Kaplan, E., Ober, BA. California Verbal Learning Test-Children's Version. San Antonio, TX: The Psychological Corporation; 1994.

Delis, DC., Kramer, JH., Kaplan, E., Ober, BA. CVLT-II: California verbal learning test: adult version. Psychological Corporation; 2000.

Di Martino A, Zuo XN, Kelly C, Grzadzinski R, Mennes M, Schvarcz A, ... Milham MP. Shared and distinct intrinsic functional network centrality in autism and attention-deficit/hyperactivity disorder. Biological Psychiatry. 2013; 74(8):623-632. [PubMed: 23541632]

Dunn, LM., Dunn, DM. Pearson Assessments. 2007. PPVT-4: Peabody picture vocabulary test.

Eiraldi RB, Power TJ, Karustis JL, Goldstein SG. Assessing ADHD and comorbid disorders in children: the Child Behavior Checklist and the Devereux Scales of Mental Disorders. Journal of Clinical Child Psychology. 2000; 29(1):3-16. [PubMed: 10693028]

Elliott, C. Differential Ability Scales. 2. San Antonio, TX: Harcourt Assessment; 2007. 
Fair DA, Bathula D, Nikolas MA, Nigg JT. Distinct neuropsychological subgroups in typically developing youth inform heterogeneity in children with ADHD. Proceedings of the National Academy of Sciences. 2012; 109(17):6769-6774.

Faraone SV, Doyle AE. The nature and heritability of attention-deficit/hyperactivity disorder. Child and Adolescent Psychiatric Clinics of North America. 2001; 10(2):299-316. [PubMed: 11351800]

Gadow, KD., Sprafkin, J. Child and Adolescent Symptom Inventory-5. Stony Brook, NY: Checkmate Plus; 2015.

Gau SSF, Shang CY. Executive functions as endophenotypes in ADHD: Evidence from the Cambridge Neuropsychological Test Battery (CANTAB). Journal of Child Psychology and Psychiatry. 2010; 51(7):838-849. [PubMed: 20085608]

Geurts HM, Verte S, Oosterlaan J, Roeyers H, Sergeant JA. How specific are executive functioning deficits in attention deficit hyperactivity disorder and autism? Journal of Child Psychology and Psychiatry. 2004; 45(4):836-854. [PubMed: 15056314]

Gilman SR, Iossifov I, Levy D, Ronemus M, Wigler M, Vitkup D. Rare de novo variants associated with autism implicate a large functional network of genes involved in formation and function of synapses. Neuron. 2011; 70(5):898-907. [PubMed: 21658583]

Goldberg MC, Mostofsky SH, Cutting LE, Mahone EM, Astor BC, Denckla MB, Landa RJ. Subtle executive impairment in children with autism and children with ADHD. Journal of Autism and Developmental Disorders. 2005; 35(3):279-293. [PubMed: 16119469]

Gordon-Lipkin E, Foster J, Peacock G. Whittling Down the Wait Time: Exploring Models to Minimize the Delay from Initial Concern to Diagnosis and Treatment of Autism Spectrum Disorder. Pediatric Clinics of North America. 2016; 63(5):851-859. [PubMed: 27565363]

Hill EL, Bird CM. Executive processes in Asperger syndrome: Patterns of performance in a multiple case series. Neuropsychologia. 2006; 44(14):2822-2835. [PubMed: 16930637]

Hus V, Bishop S, Gotham K, Huerta M, Lord C. Factors influencing scores on the social responsiveness scale. Journal of Child Psychology and Psychiatry. 2013a; 54(2):216-224. [PubMed: 22823182]

Hus V, Bishop S, Gotham K, Huerta M, Lord C. Commentary: advancing measurement of ASD severity and social competence: a reply to Constantino and Frazier (2013). Journal of Child Psychology and Psychiatry. 2013b; 54(6):698-700. [PubMed: 23488613]

Insel TR. The NIMH research domain criteria (RDoC) project: precision medicine for psychiatry. American Journal of Psychiatry. 2014; 171(4):395-397. [PubMed: 24687194]

Iossifov I, O'Roak BJ, Sanders SJ, Ronemus M, Krumm N, Levy D, ... Smith JD. The contribution of de novo coding mutations to autism spectrum disorder. Nature. 2014; 515(7526):216-221. [PubMed: 25363768]

Iossifov I, Ronemus M, Levy D, Wang Z, Hakker I, Rosenbaum J, ... Kendall J. De novo gene disruptions in children on the autistic spectrum. Neuron. 2012; 74(2):285-299. [PubMed: 22542183]

Jung T, Wickrama KAS. An introduction to latent class growth analysis and growth mixture modeling. Social and Personality Psychology Compass. 2008; 2(1):302-317.

Karalunas SL, Fair D, Musser ED, Aykes K, Iyer SP, Nigg JT. Subtyping attention-deficit/hyperactivity disorder using temperament dimensions: toward biologically based nosologic criteria. JAMA psychiatry. 2014; 71(9):1015-1024. [PubMed: 25006969]

Kotte A, Joshi G, Fried R, Uchida M, Spencer A, Woodworth KY, ... Biederman J. Autistic traits in children with and without ADHD. Pediatrics. 2013; 132(3):e612-e622. [PubMed: 23979086]

Krumm N, Turner TN, Baker C, Vives L, Mohajeri K, Witherspoon K, ... Leal SM. Excess of rare, inherited truncating mutations in autism. Nature genetics. 2015; 47(6):582-588. [PubMed: 25961944]

Lahey BB, Pelham WE, Loney J, Lee SS, Willcutt E. Instability of the DSM-IV subtypes of ADHD from preschool through elementary school. Archives of General Psychiatry. 2005; 62(8):896-902. [PubMed: 16061767]

Loehlin, JC. Latent variable models: An introduction to factor, path, and structural equation analysis. Hillsdale, NJ: Lawrence Erlbaum Associates; 2004. 
Lord, C., Rutter, M., DiLavore, PC. Autism Diagnostic Observation Schedule (Modules 1-4). 2. Torrance, CA: Western Psychological Services; 2012.

Matson JL, Shoemaker M. Intellectual disability and its relationship to autism spectrum disorders. Research in Developmental Disabilities. 2009; 30(6):1107-1114. [PubMed: 19604668]

McGrath LM, Braaten EB, Doty ND, Willoughby BL, Wilson HK, O’Donnell EH, ... Doyle AE. Extending the 'cross-disorder' relevance of executive functions to dimensional neuropsychiatric traits in youth. Journal of Child Psychology and Psychiatry. 2016; 57(4):462-471. [PubMed: 26411927]

McGrath LM, Pennington BF, Shanahan MA, Santerre-Lemmon LE, Barnard HD, Willcutt EG, ... Olson RK. A multiple deficit model of reading disability and attention-deficit/hyperactivity disorder: Searching for shared cognitive deficits. Journal of Child Psychology and Psychiatry. 2011; 52(5):547-557. [PubMed: 21126246]

McRae JF, Clayton S, Fitzgerald TW, Kaplanis J, Prigmore E, Rajan D, ... Ambridge K. Prevalence and architecture of de novo mutations in developmental disorders. Nature. 2017; 542(7642):433433. [PubMed: 28135719]

Miyake A, Friedman NP, Emerson MJ, Witzki AH, Howerter A, Wager TD. The unity and diversity of executive functions and their contributions to complex 'Frontal Lobe' tasks: A latent variable analysis. Cognitive Psychology. 2000; 41(1):49-100. [PubMed: 10945922]

Múthen, LK., Múthen, B0. Mplus user's guide. 7. Los Angeles, CA: Múthen \& Múthen; 1998-2012.

Murray MJ, Mayes SD, Smith LA. Brief report: excellent agreement between two brief autism scales (Checklist for Autism Spectrum Disorder and Social Responsiveness Scale) completed independently by parents and the Autism Diagnostic Interview-Revised. Journal of autism and developmental disorders. 2011; 41(11):1586-1590. [PubMed: 21301946]

Nydén A, Gillberg C, Hjelmquist E, Heiman M. Executive function/attention deficits in boys with Asperger syndrome, attention disorder and reading/writing disorder. Autism. 1999; 3(3):213-228.

Nydén A, Hagberg B, Goussé V, Rastam M. A cognitive endophenotype of autism in families with multiple incidence. Research in Autism Spectrum Disorders. 2011; 5(1):191-200.

Neale BM, Medland SE, Ripke S, Asherson P, Franke B, Lesch KP, ... Daly M. Meta-analysis of genome-wide association studies of attention-deficit/hyperactivity disorder. Journal of the American Academy of Child \& Adolescent Psychiatry. 2010; 49(9):884-897. [PubMed: 20732625]

Ostrander R, Weinfurt KP, Yarnold PR, August GJ. Diagnosing attention deficit disorders with the Behavioral Assessment System for Children and the Child Behavior Checklist: Test and construct validity analyses using optimal discriminant classification trees. Journal of Consulting and Clinical Psychology. 1998; 66(4):660. [PubMed: 9735584]

O’Roak BJ, Deriziotis P, Lee C, Vives L, Schwartz JJ, Girirajan S, ... Rieder MJ. Exome sequencing in sporadic autism spectrum disorders identifies severe de novo mutations. Nature Genetics. 2011; 43(6):585-589. [PubMed: 21572417]

O’Roak BJ, Stessman HA, Boyle EA, Witherspoon KT, Martin B, Lee C, ... Bernier R. Recurrent de novo mutations implicate novel genes underlying simplex autism risk. Nature Communications. 2014; 5(5595)

Ozonoff S, Jensen J. Brief report: Specific executive function profiles in three neurodevelopmental disorders. Journal of Autism and Developmental Disorders. 1999; 29(2):171-177. [PubMed: 10382139]

Ozonoff S, Pennington BF, Rogers SJ. Executive function deficits in high-functioning autistic individuals: relationship to theory of mind. Journal of child Psychology and Psychiatry. 1991; 32(7):1081-1105. [PubMed: 1787138]

Pennington BF, Ozonoff S. Executive functions and developmental psychopathology. Journal of Child Psychology and Psychiatry. 1996; 37(1):51-87. [PubMed: 8655658]

Poelmans G, Pauls DL, Buitelaar JK, Franke B. Integrated genome-wide association study findings: Identification of a neurodevelopmental network for attention deficit hyperactivity disorder. American Journal of Psychiatry. 2011; 168(4):365-377. [PubMed: 21324949]

Pugliese CE, Kenworthy L, Bal VH, Wallace GL, Yerys BE, Maddox BB, ... Herrington JD. Replication and comparison of the newly proposed ADOS-2, module 4 algorithm in ASD without 
ID: A multi-site study. Journal of Autism and Developmental Disorders. 2015; 45(12):3919-3931. [PubMed: 26385796]

Reiersen AM, Constantino JN, Volk HE, Todd RD. Autistic traits in a population-based ADHD twin sample. Journal of Child Psychology and Psychiatry. 2007; 48(5):464-472. [PubMed: 17501727]

Rommelse NN, Altink ME, Fliers EA, Martin NC, Buschgens CJ, Hartman CA, ... Oosterlaan J. Comorbid problems in ADHD: Degree of association, shared endophenotypes, and formation of distinct subtypes. Implications for a future DSM. Journal of Abnormal Child Psychology. 2009; 37(6):793-804. [PubMed: 19308723]

Rutter, M., Le Couteur, A., Lord, C. Autism Diagnostic Interview-Revised. Vol. 29. Los Angeles, CA: Western Psychological Services; 2003. p. 30

Simonoff E, Pickles A, Charman T, Chandler S, Loucas T, Baird G. Psychiatric disorders in children with autism spectrum disorders: Prevalence, comorbidity, and associated factors in a populationderived sample. Journal of the American Academy of Child \& Adolescent Psychiatry. 2008; 47(8): 921-929. [PubMed: 18645422]

Sinzig J, Morsch D, Bruning N, Schmidt MH, Lehmkuhl G. Inhibition, flexibility, working memory and planning in autism spectrum disorders with and without comorbid ADHD-symptoms. Child and Adolescent Psychiatry and Mental Health. 2008; 2(1):4. [PubMed: 18237439]

Sinzig J, Walter D, Doepfner M. Attention deficit/hyperactivity disorder in children and adolescents with autism spectrum disorder: symptom or syndrome? Journal of Attention Disorders. 2009; 13(2):117-126. [PubMed: 19380514]

Sparrow, SS., Cicchetti, DV., Balla, DA. Vineland Adaptive Behavior Scales. 2. Circle Pines, MN: Pearson Assessments; 2005.

Spearman, C. The abilities of man. 1927.

Tackett JL, Lahey BB, van Hulle C, Waldman I, Krueger RF, Rathouz PJ. Common genetic influences on negative emotionality and a general psychopathology factor in childhood and adolescence. Journal of Abnormal Psychology. 2013; 122(4):1142-1153. [PubMed: 24364617]

Taurines R, Schwenck C, Westerwald E, Sachse M, Siniatchkin M, Freitag C. ADHD and autism: Differential diagnosis or overlapping traits? A selective review. ADHD Attention Deficit and Hyperactivity Disorders. 2012; 4(3):115-139. [PubMed: 22851255]

Todd RD, Huang H, Smalley SL, Nelson SF, Willcutt EG, Pennington BF, ... Neuman RJ. Collaborative analysis of DRD4 and DAT genotypes in population-defined ADHD subtypes. Journal of Child Psychology and Psychiatry. 2005; 46(10):1067-1073. [PubMed: 16178930]

van der Meer JM, Oerlemans AM, van Steijn DJ, Lappenschaar MG, de Sonneville LM, Buitelaar JK, Rommelse NN. Are autism spectrum disorder and attention-deficit/hyperactivity disorder different manifestations of one overarching disorder? Cognitive and symptom evidence from a clinical and population-based sample. Journal of the American Academy of Child \& Adolescent Psychiatry. 2012; 51(11):1160-1172. [PubMed: 23101742]

Van Steensel FJ, Bögels SM, de Bruin EI. Psychiatric comorbidity in children with autism spectrum disorders: A comparison with children with ADHD. Journal of Child and Family Studies. 2013; 22(3):368-376. [PubMed: 23524401]

Weintraub S, Dikmen SS, Heaton RK, Tulsky DS, Zelazo PD, Bauer PJ, ... Fox NA. Cognition assessment using the NIH Toolbox. Neurology. 2013; 80(11 Supplement 3):S54-S64. [PubMed: 23479546]

Williams KT. Expressive Vocabulary Test Second Edition (EVT ${ }^{\mathrm{TM}}$ 2). J Am Acad Child Adolesc Psychiatry. 1997; 42:864-872.

Willcutt EG. The prevalence of DSM-IV attention-deficit/hyperactivity disorder: a meta-analytic review. Neurotherapeutics. 2012; 9(3):490-499. [PubMed: 22976615]

Willcutt EG, Doyle AE, Nigg JT, Faraone SV, Pennington BF. Validity of the executive function theory of attention-deficit/hyperactivity disorder: A meta-analytic review. Biological Psychiatry. 2005; 57(11):1336-1346. [PubMed: 15950006] 


\section{KEY POINTS}

- $\quad$ ASD and inattention problems are highly comorbid

- Putative genetic mutations account for shared variance between symptoms of autism and inattention

- $\quad$ Cognitive deficits associated with autism and ADHD may be better conceptualized as comorbidities, rather than endophenotypes

- Genetic events associated with ASD may provide leads for investigating the genetic etiology of ADHD 


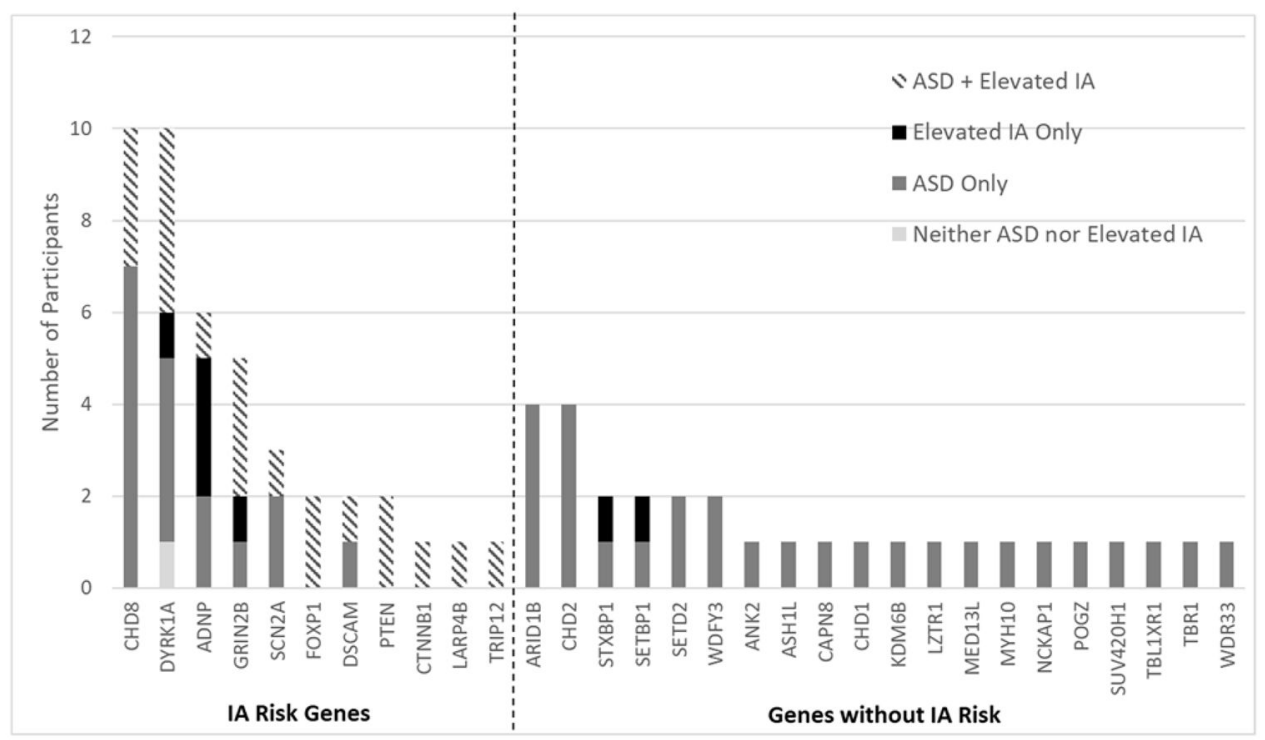

Figure 1.

Number of individuals with ASD and/or Elevated IA by primary affected gene. Eleven IA Risk Genes were defined as those with any individuals with ASD+ Elevated IA (slanted stripe) or Elevated IA Only (solid black). Some individuals had mutations on additional genes (see Supplementary Table S1). 

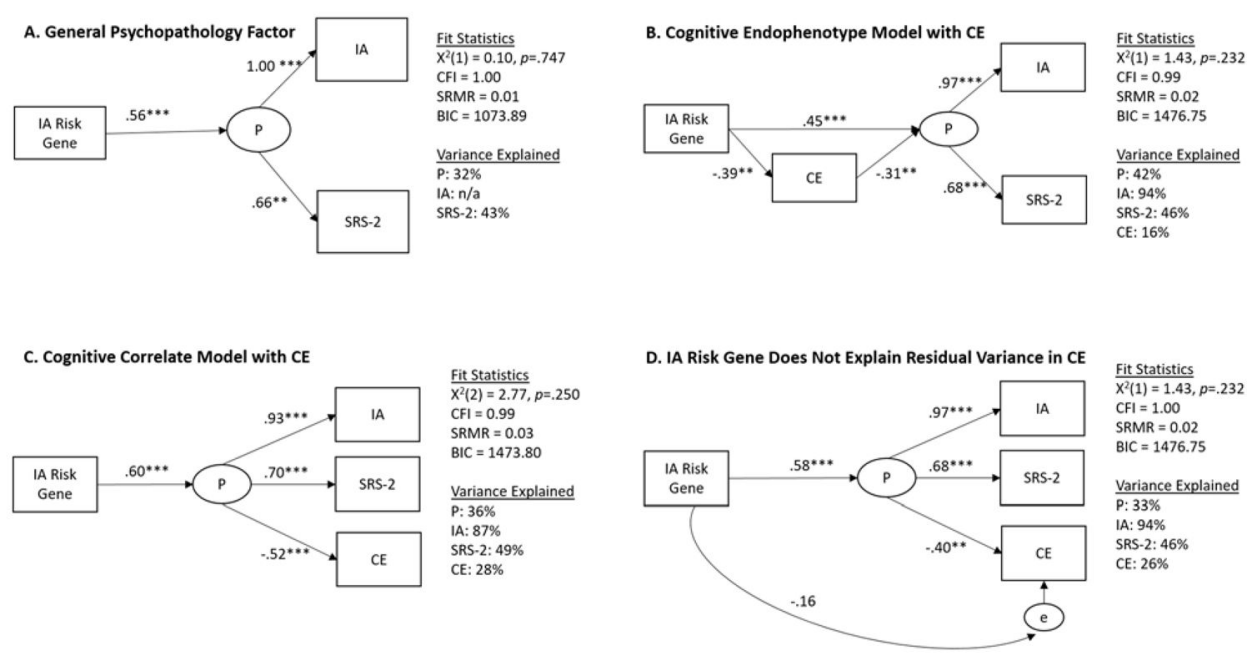

Figure 2.

A) IA Risk Gene categorization explains $P$, a latent variable reflecting shared variance between IA and SRS-2. B) Common executive mediates the association between genetic risk and $P$. C) IA Risk Gene categorization explains shared variance among IA, ASD and CE. D) IA Risk Gene categorization does not explain residual variance in $\mathrm{CE}$ when $\mathrm{CE}$ is explained by $P$. IA Risk Gene $=1$, LGDM without IA Risk $=0$. Path weights are standardized Beta coefficients. $* * * p<.001 ; * * p<.01$. Note that in Model A, the residual variance of IA severity is set to zero. 


\section{Table 1}

Participant Demographics

\begin{tabular}{lccc}
\hline & LGDM without IA Risk & $\underline{\text { IA Risk Gene }}$ & $\underline{\text { Total }}$ \\
$N$ & 26 & 47 & 73 \\
Age in months (SD) & $167(51)$ & $121(56)$ & $138(58)$ \\
Female (\%) & $5(19)$ & $15(32)$ & $20(27 \%)$ \\
Autism Spectrum Disorder (\%) & $26(100 \%)$ & $39(83 \%)$ & $65(89 \%)$ \\
Elevated IA (\%) & 0 & $27(57 \%)$ & $27(37 \%)$ \\
$\%$ Household Income $\leq \$ 75,000$ & $14 \%$ & $30 \%$ & $25 \%$ \\
Full Scale IQ (SD) & $78(26)$ & $56(25)$ & $65(27)$ \\
IA Severity (SD) & $61(8)$ & $74(9)$ & $69(11)$ \\
SRS-2 Severity (SD) & $70(11)$ & $79(12)$ & $76(12)$ \\
Adaptive Functioning (SD) & $68(14)$ & $59(14)$ & $62(15)$ \\
\hline
\end{tabular}

Note: Elevated IA defined as 6 or more CASI-5 Inattention symptoms and Achenbach Attention Problems T score 270 . IA and SRS-2 severity scales are T-scores with $M=50, S D=10$. Adaptive Functioning was measured with the Vineland Adaptive Behavior Composite Standard Score, $M=100, S D=15$. 
Table 2

Cognitive Factor Scores of Participants with and without IA Risk Gene Events

\begin{tabular}{lccc}
\hline & LGDM without IA Risk (n=26) & IA Risk Gene (n=47) & $\boldsymbol{t}(\mathbf{7 1})$ \\
\cline { 2 - 4 } Verbal Memory $M(\mathrm{SD})$ & $1.25(13.94)$ & $-10.96(11.39)$ & $4.05^{* * *}$ \\
Verbal Fluency $M$ (SD) & $1.69(16.64)$ & $-12.89(17.60)$ & $3.46^{* * *}$ \\
Visual-Spatial $M(\mathrm{SD})$ & $3.18(15.58)$ & $-14.71(14.18)$ & $4.98^{* * *}$ \\
Executive Control $M(\mathrm{SD})$ & $.25(3.86)$ & $-2.87(3.36)$ & $3.61^{* * *}$ \\
\hline
\end{tabular}

Note: Two-tailed $p$ value:

$* * * .001$

*** $<.01$. 